\title{
Pumps modelling of a sodium fast reactor design and analysis of hydrodynamic behavior
}

\author{
José Ordóñez Ródenas ${ }^{*}$, Aurelio Lázaro Chueca, and Sebastián Martorell Alsina \\ Grupo MEDASEGI, Departamento de Ingeniería Química y Nuclear - Universitat Politècnica de València, Camí de Vera s/n, \\ 46022 Valencia, Spain
}

Received: 4 May 2015 / Received in final form: 15 May 2016 / Accepted: 24 June 2016

\begin{abstract}
One of the goals of Generation IV reactors is to increase safety from those of previous generations. Different research platforms have been identified the need to improve the reliability of the simulation tools to ensure the capability of the plant to accommodate the design basis transients established in preliminary safety studies. The paper describes the modelling of primary pumps in advanced sodium cooled reactors using the TRACE code. Following the implementation of the models, the results obtained in the analysis of different design basis transients are compared with the simplifying approximations used in reference models. The paper shows the process to obtain a consistent pump model of the ESFR (European Sodium Fast Reactor) design and the analysis of loss of flow transients triggered by pumps coast-down analyzing the thermal hydraulic neutronic coupled system response. A sensitivity analysis of the system pressure drops effect and the other relevant parameters that influence the natural convection after the pumps coast-down is also included.
\end{abstract}

\section{Introduction}

The technological challenge for Generation IV reactors is defined in five areas: sustainability, economics, safety, security and non-proliferation. Trying to meet these technology goals, new systems are designed to achieve a number of long-term benefits that will help nuclear energy to play an essential role in the electric production of countries.

The analysis of transients generated by different design basis accidents is an important starting point in the design of new reactors. To optimize these analyzes it is necessary to improve the tools that are available currently seeking systems to better reflect the reality, thus increasing reliability and security level.

This paper will describe the modelling process of the pumps of a fast reactor design cooled by liquid sodium, in particular the ESFR (European Sodium Fast Reactor) design[1] using the TRACE code. After modelling, different simulations were performed comparing the results with those obtained in a reference model.

The work was carried out in a one-dimensional and threedimensional model of the same reactor in which the mass flow was implemented by means of a Time Dependent Junction component that impose the mass flow level through the system, limiting partially the response of the system. Models and nodalizations are described in the available literature $[2,3]$.

\footnotetext{
* e-mail: joorro1@etsii.upv.es
}

The results show how pumps act taking the system to regimes consistent with those obtained in the reference models. A sensitivity analysis of relevant parameters that influence the natural convection after the pumps coast-down is also included.

The main objective of this work is to obtain a model that represents, in a closer reality mode, the evolution of the reactor during pump coast-down transient, identifying also areas of improvement for future studies.

\section{Cooling system}

The ESFR design [4] is a sodium cooled fast reactor of industrial size. The reactor has three cooling systems. A primary system pool type cooled by sodium housing the core, three mechanical primary pumps (PP), six intermediate heat exchangers (IHX) and six decay heat removal (DHR) (Fig. 1). The secondary system consists of six intermediate loops, each one equipped with one IHX on the reactor side and six modular sodium/water steam generators $(\mathrm{SG})$. The tertiary system consists therefore of 36 separate circuits. This configuration is the so-called modular configuration and enhances the safety of the system by limiting the effects of a possible sodium water reaction caused by a steam tube rupture.

The TRACE code was adapted to the new coolant replacing correlations governing the heat transfer, replacing includes ones in the original code by others identified in the available bibliography [5]. 


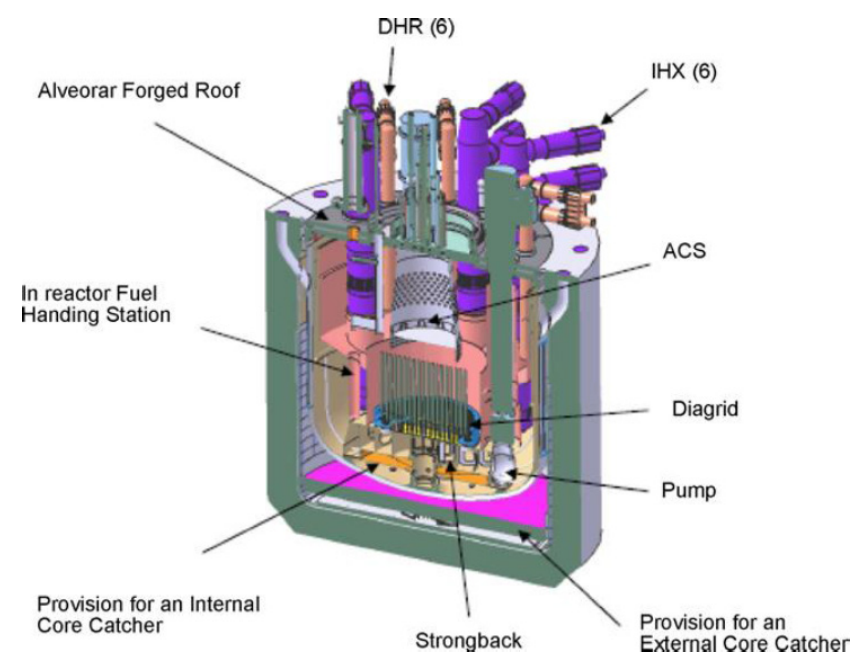

Fig. 1. ESFR pool-primary vessel scheme [1].

Table 1. Reactor nominal parameters.

\begin{tabular}{ll}
\hline Variables & Parameter \\
\hline Reactor power $($ MWth $)$ & 3600 \\
Core inlet temperature $\left({ }^{\circ} \mathrm{C}\right)$ & 395 \\
Core outlet temperature $\left({ }^{\circ} \mathrm{C}\right)$ & 545 \\
IHX inlet temperature $\left({ }^{\circ} \mathrm{C}\right)$ & 340 \\
SG outlet temperature $\left({ }^{\circ} \mathrm{C}\right)$ & 490 \\
SG pressure $($ bar $)$ & 185 \\
Primary mass flow $(\mathrm{kg} / \mathrm{s})$ & 20,860 \\
Secondary mass flow $(\mathrm{kg} / \mathrm{s})$ & 16,907 \\
Tertiary mass flow $(\mathrm{kg} / \mathrm{s})$ & 1650 \\
\hline
\end{tabular}

The main parameters of nominal operation are listed in Table 1.

\subsection{One-dimensional model}

- Primary system: One loop with a heat exchanger connected to the secondary and a pump recirculating the coolant through the reactor core.

- Secondary system: One loop with two heat exchangers, each connected to the primary and tertiary respectively, and a pump to recirculate the coolant through the system.

- Tertiary system: This system is represented by a PIPE component that absorbs heat provided by the secondary loop, mass flow, pressure and inlet temperature are imposed as boundary conditions.

The core is represented by seven different cooling groups attending to the power profile in BOL conditions (Beginning Of Life). These groups correspond to; one group to the elements of the inner zone, two groups for the outer zone, one group for the control elements, one group for the reflector, one group for the by-pass and a group for Hot Fuel Assembly, associated with the peak present in the power profile. The neutronic feedback has been implemented with a point kinetic neutronic model.

\subsection{Three-dimensional model}

In order to take into account localized phenomena, a threedimensional modelization is required. The primary system was replaced by a three-dimensional vessel component thermally linked with three secondary and tertiary loops consistently.

The core is now represented by 14 axial levels, 10 correspond to the active part, 4 radial rings (one for the inner core, two for the outside and one for the reflector and control elements). As the one-dimensional, core has been implemented with a point kinetic neutronic model.

Other axial levels (1-5) and (19-25) represent the lower (cold) and higher pool (hot) primary system. IHX are modeled with three-dimensional structures and coupled in each azimuthal sector of the element VESSEL. Consequently, the modelling of the secondary and tertiary circuits was split into three equivalent independent circuits each coupled to one of the IHX integrated in each azimuthal sector.

In both primary and secondary circuits, three pumps that recirculate coolant through the system, have been modeled. As in the one-dimensional model, in the tertiary, the mass flow is imposed without any pump.

\section{Pump modelling}

The pump modelling in TRACE is based on the standard homologous-curves approach. These curves represent the performance of the pump in a normalized format, giving the normalized pump head as a function of the normalized volumetric flow and normalized pump speed.

Homologous curves (one curve segment represents a family of curves) are used for this description because of their simplicity. These curves describe, in a compact manner, all operating states of the pump obtained by combining positive or negative pump-impeller angular velocities with positive or negative fluid volumetric flows [6].

In the one-dimensional model there is only one loop with its pump in each system, while in the threedimensional model there are three loops per system and, in each one, a pump. Consequently, each of these pumps works with $1 / 3$ of the flow of the one-dimensional model.

The pumps modelling was made from two head-flow curves (Figs. 2 and 3) extracted from the design's technical specifications in which the pumps work in very similar conditions. With a nominal flow rate of $7.50 \mathrm{~m}^{3} / \mathrm{s}$ and a nominal angular speed of $550 \mathrm{rpm}$.

As already mentioned, the values of the previous curves have to be normalized respect to nominal

$$
H=\frac{H}{H_{N}} ; q=\frac{Q}{Q_{N}} ; \omega=\frac{\Omega}{\Omega_{N}} .
$$




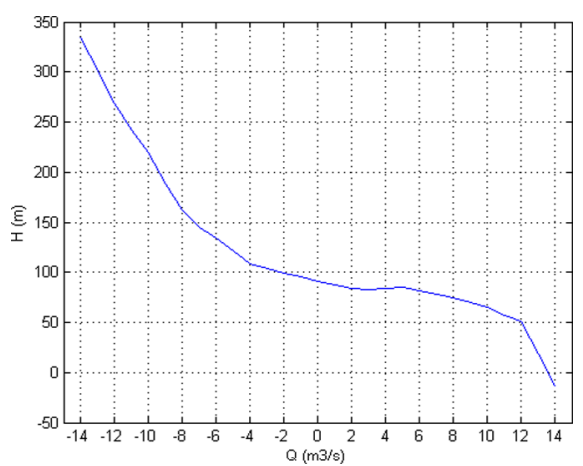

Fig. 2. $H-Q$ pump curve (550 rpm).

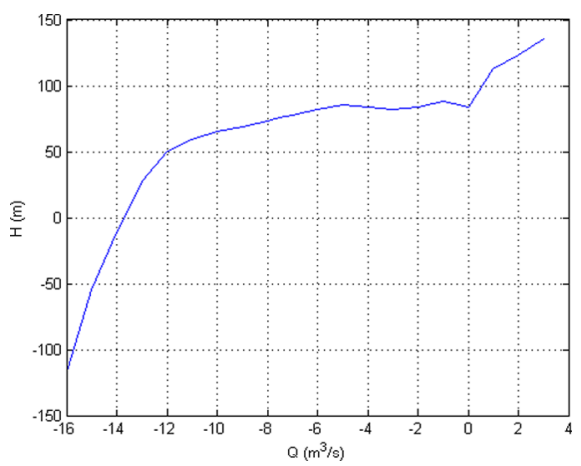

Fig. 3. $H-Q$ pump curve $(-550 \mathrm{rpm})$.

Table 2. Definition of segments and work areas [6].

\begin{tabular}{lllll}
\hline $\begin{array}{l}\text { Curve } \\
\text { segment }\end{array}$ & $\left|\frac{q}{\omega}\right|$ & $\omega$ & $q$ & Correlation \\
\hline 1 & $\leq 1$ & $>0$ & N $/ \mathrm{A}$ & $\frac{h}{\omega^{2}}=f\left(\frac{q}{\omega}\right)$ \\
4 & $\leq 1$ & $<0$ & N $/ \mathrm{A}$ & $\frac{h}{q^{2}}=f\left(\frac{\omega}{q}\right)$ \\
2 & $>1$ & $\mathrm{~N} / \mathrm{A}$ & $>0$ & \\
3 & $>1$ & N $/ \mathrm{A}$ & $<0$ & \\
\hline
\end{tabular}

For each work area, first is needed to establish pump operating conditions by means of hypotheses shown in Table 2 and to obtain the normalized values for each work area.

With normalized values and taking into account the definition of working areas, it is possible to build a graphic that represents the homologous curves as shown in Figures 4 and 5 .

TRACE code also requires a second set of curves similar to the above representing the normalized torque as a function of the normalized volumetric flow and normalized pump speed. Parameters are also extracted from the design's technical specification.

The $H-Q$ curves used are those corresponding to PPs that, according to design's technical specifications, operate with a mass flow level of $7.50 \mathrm{~m}^{3} / \mathrm{s}$, very close to threedimensional model pumps and at identical working conditions. Characteristic parameters of pumps are shown in Table $3(1 \mathrm{D})$ and Table $4(3 \mathrm{D})$.

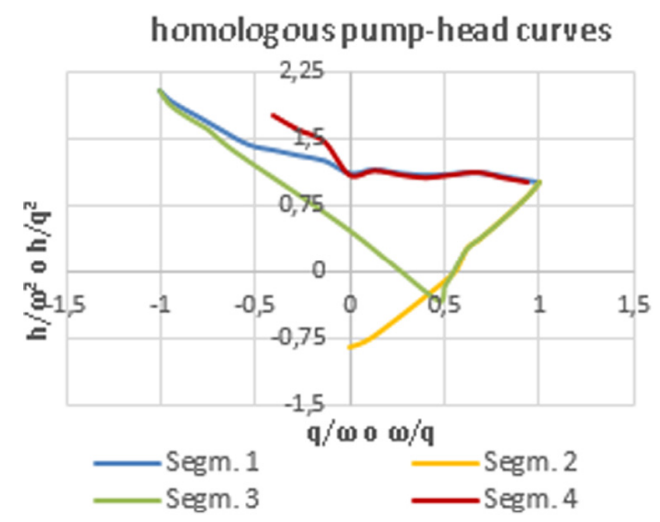

Fig. 4. Homologous pump-head curves.

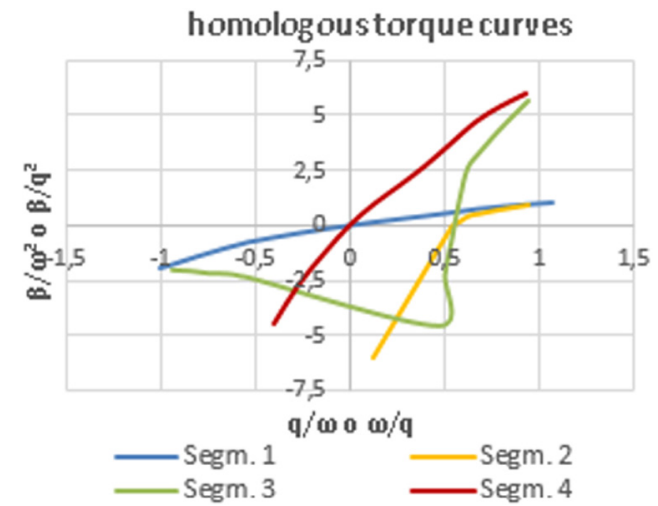

Fig. 5. Homologous pump-torque curves.

Table 3. Characteristics pump parameters (1D).

\begin{tabular}{lll}
\hline Variables & Primary & Secondary \\
\hline$H_{N}\left(\mathrm{~m}^{2} / \mathrm{s}^{2}\right)$ & 753.4 & 753.4 \\
$Q_{N}\left(\mathrm{~m}^{3} / \mathrm{s}\right)$ & 24.2 & 19.3 \\
$\Omega_{N}(\mathrm{rpm})$ & 550 & 550 \\
Inertia $\left(\mathrm{kg} \mathrm{m}^{2}\right)$ & $51,892.5$ & $43,126.6$ \\
Torque $(\mathrm{N} \mathrm{m})$ & $260,856.8$ & $259,858.8$ \\
\hline
\end{tabular}

Table 4. Characteristics pump parameters (3D).

\begin{tabular}{lll}
\hline Variables & Primary & Secondary \\
\hline$H_{N}\left(\mathrm{~m}^{2} / \mathrm{s}^{2}\right)$ & 753.4 & 753.4 \\
$Q_{N}\left(\mathrm{~m}^{3} / \mathrm{s}\right)$ & 8.1 & 6.43 \\
$\Omega_{N}(\mathrm{rpm})$ & 550 & 550 \\
Inertia $\left(\mathrm{kg} \mathrm{m}^{2}\right)$ & $18,081.0$ & $13,531.9$ \\
Torque $(\mathrm{N} \mathrm{m})$ & $91,243.4$ & $73,696.8$ \\
\hline
\end{tabular}

\section{Simulations}

First, steady-state conditions were verified in both, 1D and 3D models, comparing them with the design's values.

Once steady-state was verified, a transient [3] consisting of the mass flow reduction of PPs were performed, in both models. 
Table 5. Steady-state results (1D).

\begin{tabular}{llll}
\hline & Pumps & Reference & Error \\
\hline$Q_{N}$ primary $\left(\mathrm{m}^{3} / \mathrm{s} ; \mathrm{kg} / \mathrm{s}\right)$ & $20,866.2$ & 20,860 & $0.030 \%$ \\
$Q_{N}$ secondary $\left(\mathrm{m}^{3} / \mathrm{s} ; \mathrm{kg} / \mathrm{s}\right)$ & $16,910.3$ & $16,907.4$ & $0.017 \%$ \\
Core inlet temperature $(\mathrm{K})$ & 661.5 & 668.0 & $-6.5 \mathrm{~K}$ \\
Core outlet temperature $(\mathrm{K})$ & 811.4 & 818.0 & $-6.6 \mathrm{~K}$ \\
$\Delta T(\mathrm{~K})$ & 149.9 & 150 & $0.1 \mathrm{~K}$ \\
\hline
\end{tabular}

Table 6. Steady-state results (3D).

\begin{tabular}{lllr}
\hline & Pumps & \multicolumn{2}{l}{ Reference } \\
\hline$Q_{N}$ primary $\left(\mathrm{m}^{3} / \mathrm{s} ; \mathrm{kg} / \mathrm{s}\right)$ & $20,833.95$ & 20,859 & $-0.12 \%$ \\
$Q_{N}$ secondary $\left(\mathrm{m}^{3} / \mathrm{s} ; \mathrm{kg} / \mathrm{s}\right)$ & $16,740.3$ & $16,907.4$ & $-0.99 \%$ \\
Core inlet temperature $(\mathrm{K})$ & 658.3 & 668.0 & $-9.7 \mathrm{~K}$ \\
Core outlet temperature $(\mathrm{K})$ & 809.3 & 818.0 & $-8.7 \mathrm{~K}$ \\
$\Delta T(\mathrm{~K})$ & 151 & 150 & $1.0 \mathrm{~K}$ \\
\hline
\end{tabular}

For the one-dimensional model, the results are compared with a reference case in which the reduction in the mass flow of the coolant was calculated with RELAP code. So, in this case, the reference model is a system with that mass flow reduction imposed by a Time Dependent Junction component.

On the second hand, for the three-dimensional system the results are shown just for analyze the response to the transient with a more complex and real model.

\subsection{Steady-state}

Tables 5 and 6 show the results of both models and the error obtained between them and the reference values. Results show that all the parameters have very similar values, indicating that pump's models are correctly set. The total time required for steady-state and to set initial conditions for the transient simulation has been $10,000 \mathrm{~s}$.

\subsection{Transient analysis}

The simulated transient has been identified as basis design on preliminary safety studies. The transient simulates the total coast-down of all PPs and the failure of the reactor shutdown by the insertion of control rods. This transient is also called ULOF accident (Unprotected Loss Of Flow).

The mass flow reduction is shown in Figure 6 (1D). It is possible to see the difference between both reference and 1D-model curves. They are quite similar so the coast-down curve of the pump seems to be correct. Figure 7 shows the mass flow reduction for the 3D-model in one of three PPs.

There is an important difference between $1 \mathrm{D}$ and $3 \mathrm{D}$ model that explains why the simulation ends at around $35 \mathrm{~s}$ in the first one and the second one continues till reach the

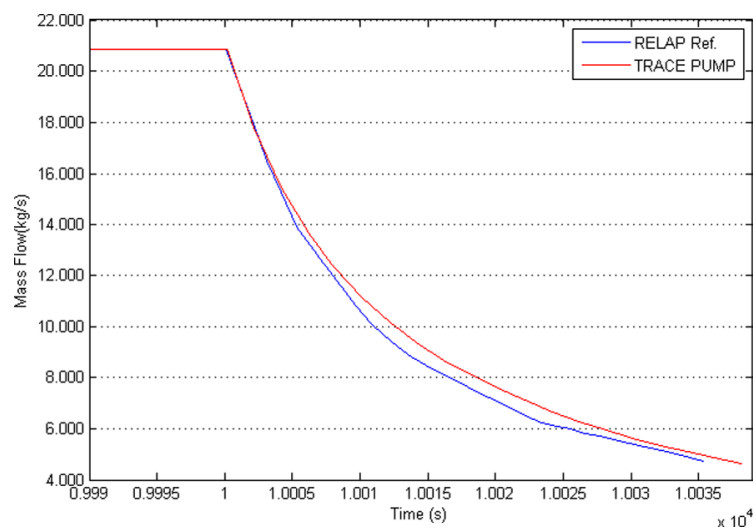

Fig. 6. Coolant mass flow (1D).

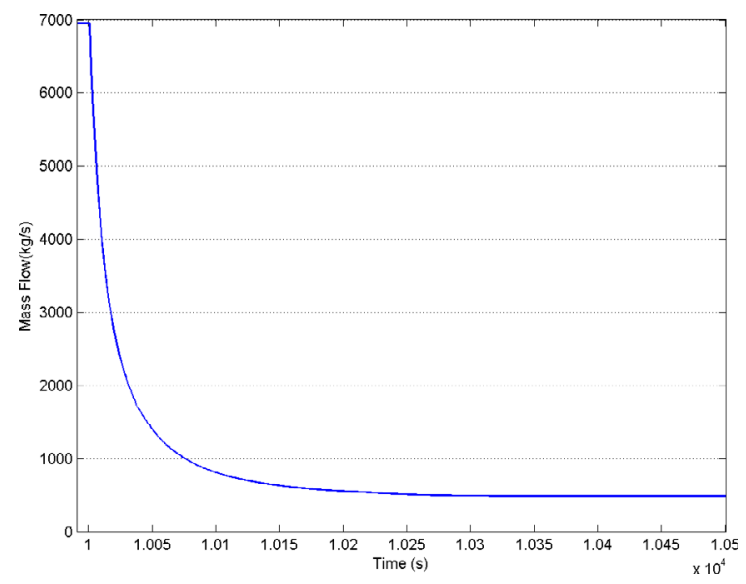

Fig. 7. Coolant mass flow in one loop (3D).

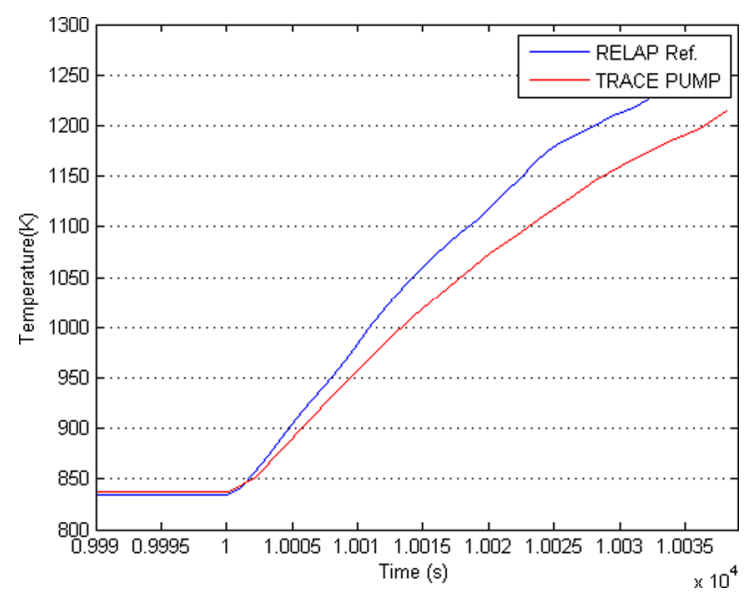

Fig. 8. HFA sodium temperature.

steady-state. As mentioned in Section 2, in the 1D-model the Hot Fuel Assembly has been implemented, corresponding to the peak in the power profile of the core. It implies that element to reach the maximum temperature. Figure 8 shows that the temperature of the sodium passing through 


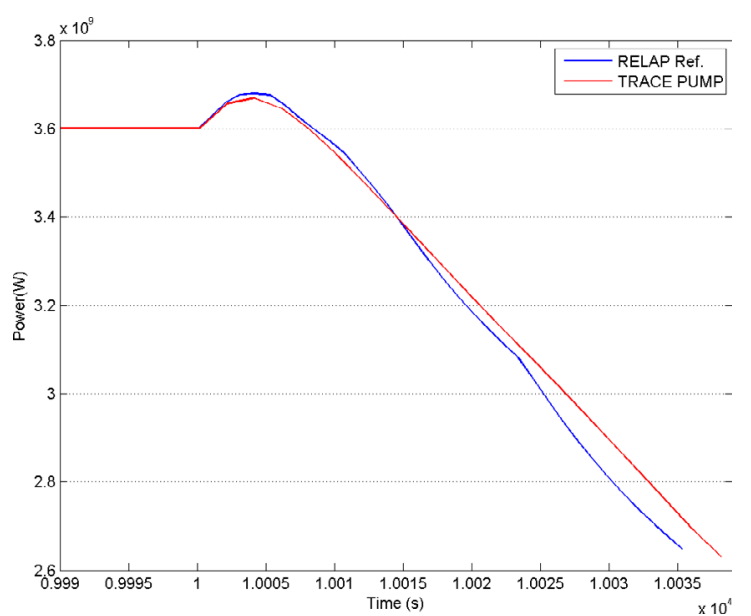

Fig. 9. Power (1D).

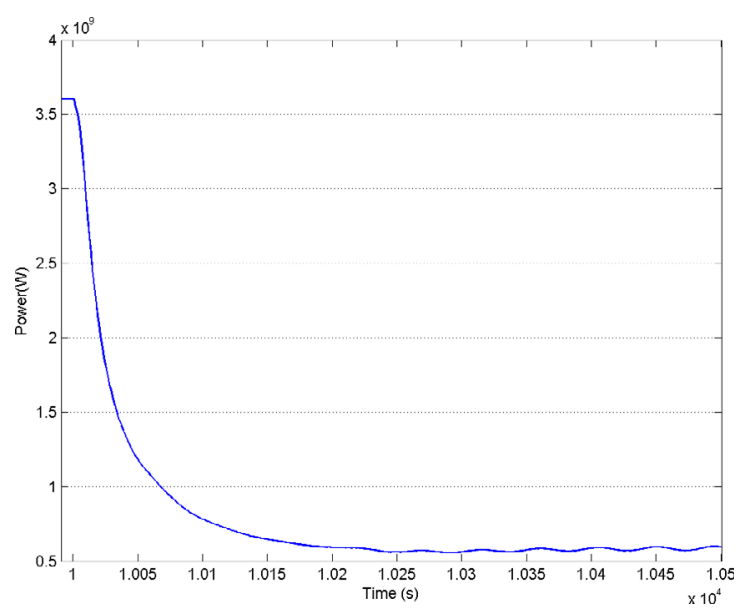

Fig. 10. Power (3D).

this element rises, due to the mass flow reduction, to its boiling point in 35 and $38 \mathrm{~s}$ for the reference and the model respectively, moment at which the code is not capable to keep calculating. On the other hand, the 3D-model has not this element implemented and the sodium does not boil in any part of the system so the simulation evolves to reach the steady-state. Because of this difference, it is possible to see a remaining coolant mass flow in natural convection of $500 \mathrm{~kg} / \mathrm{s}$ approximately for one loop, that is the $7 \%$ of the nominal flow.

Figures 9 and 10 show the power in the core. In both cases the power decreases due to, mainly, the negative reactivity of the Doppler effect. In the 3D-model, the power decreases to approximately $590 \mathrm{MW}$, but it is not constant at the steady-state, there are some instabilities.

Core outlet temperature for the 3D-model is represented in Figure 11 for the three first radial rings of the vessel. The temperature increase strongly due to the reduction of the coolant mass flow and then it is reduced till rise another equilibrium state with a higher temperature. Like power, the temperature does not maintain constant but some instabilities appear.

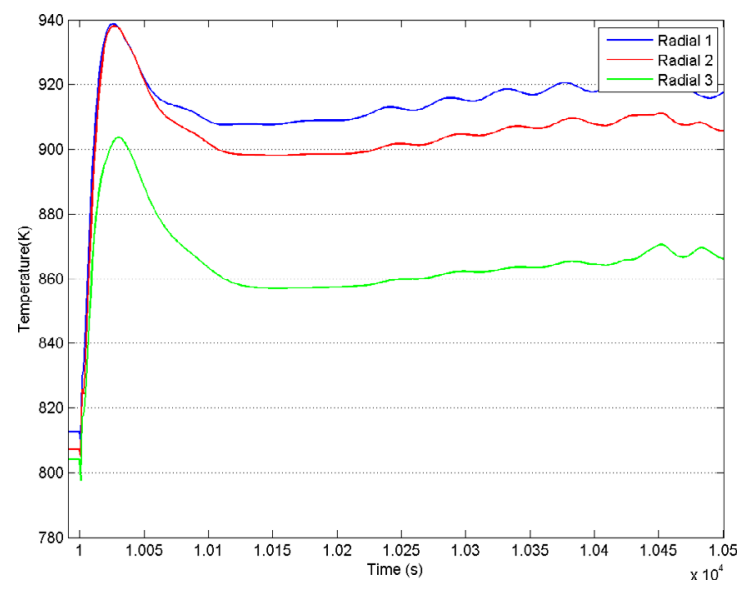

Fig. 11. Core outlet temperature (3D).

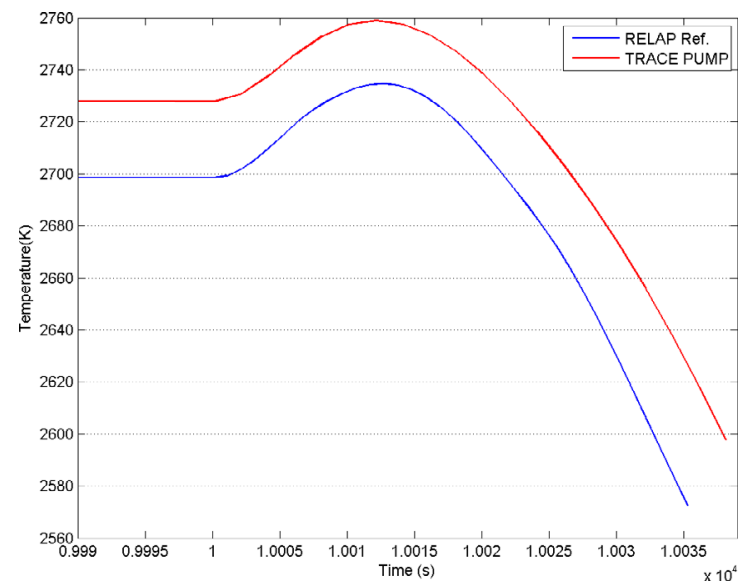

Fig. 12. HFA fuel temperature (1D).

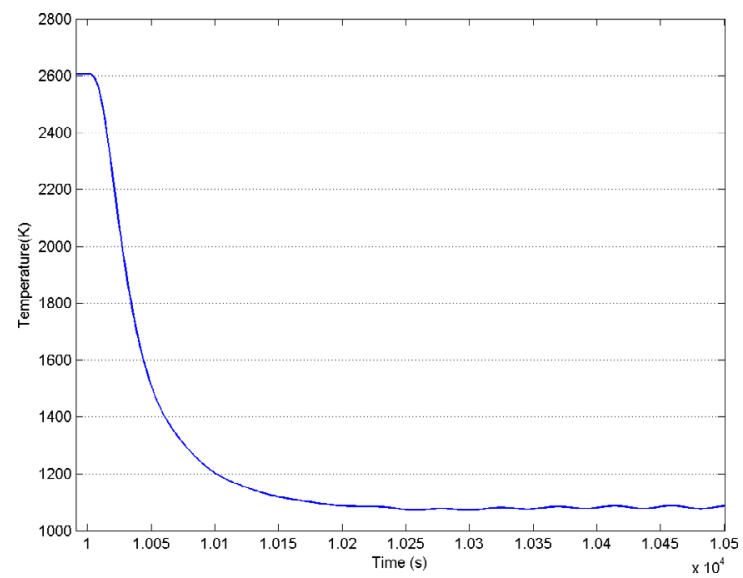

Fig. 13. Maximum fuel temperature.

The fuel temperature represented in Figure 12 (1D) and Figure $13(3 \mathrm{D})$ evolves parallel to the power decreasing because of the Doppler effect. In the 3D-model it decreases to $1100 \mathrm{~K}$ approximately. In the $1 \mathrm{D}$-model there is a difference between the reference and the model $(30 \mathrm{~K})$ due 


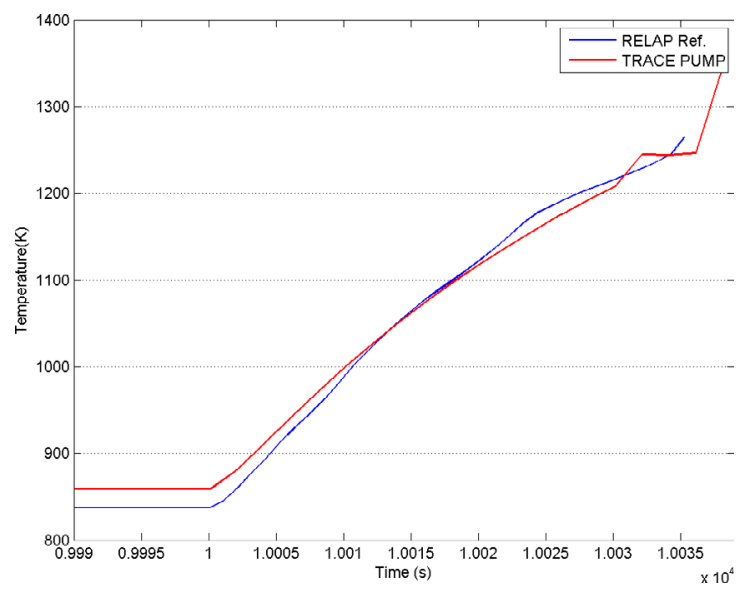

Fig. 14. HFA cladding temperature (1D).

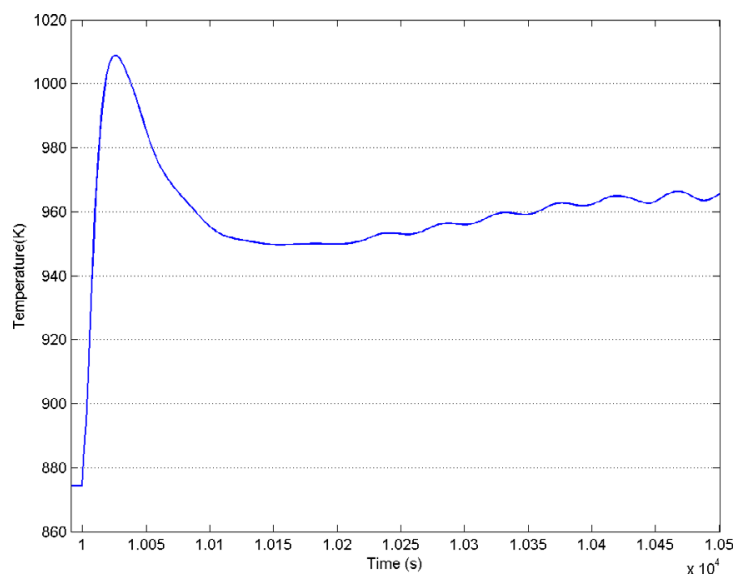

Fig. 15. Maximum cladding temperature.

to the difference in the mass flow of coolant through the Hot Fuel Assembly for both cases in the steady-state. This is due to the drop model of this component. The maximum temperature in both systems is $1759 \mathrm{~K}$ (reference) and $1735 \mathrm{~K}$ (model).

Figures 14 and 15 represent the maximum cladding temperature $(1 \mathrm{D}, 3 \mathrm{D})$. In the 3D-model the temperature, $1100 \mathrm{~K}$, is lower than in the 1D-model in which it is above $1300 \mathrm{~K}$. In the first one the temperature decrease after reaching its maximum to another equilibrium state with a higher temperature than the initial one.

In all the cases, maximum temperature in the 1D-model are higher than those of the 3D-model due to the implementation of the Hot Fuel Assembly.

\section{Sensitivity analysis}

The last part of this paper shows a sensitivity analysis of two different parameters related with the coast-down curve of pumps and with the remaining mass flow of coolant in natural convection:

- pump moment of inertia;

- mean height between core and IHX.

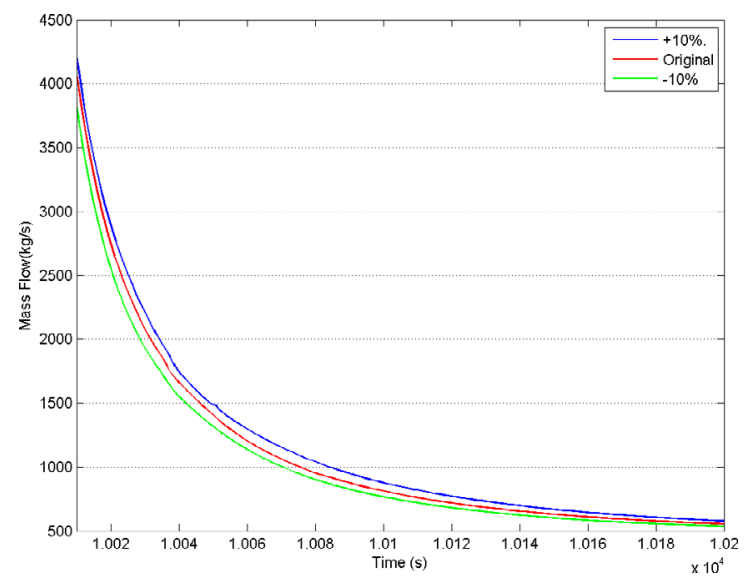

Fig. 16. Coolant mass flow reduction (\%) in one loop (3D). Moment of inertia sensitivity analysis.

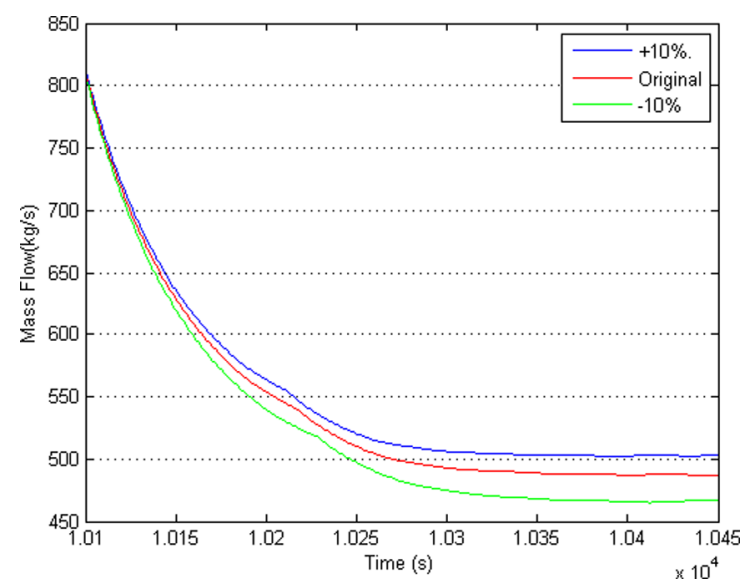

Fig. 17. Mass flow reduction (\%) in natural convection in one loop (3D). Mean height between core and IHX sensitivity analysis.

\subsection{Pump inertia}

The inertia of the pump has been modified in a range of $\pm 10 \%$ of the nominal $\left(18,081 \mathrm{~kg} \mathrm{~m}^{2}\right)$.

Figure 16 represents three mass flow curves in one loop, one for the nominal value, and two corresponding to the $\pm 10 \%$. The graphic shows how the coast-down curve varies depending of the inertia value. The difference over the nominal is around the $6 \%$. Once the steady-state is reached, the mass flow in the three cases is the same. This parameter only modifies the mass flow reduction curve.

\subsection{Mean height of heat exchange}

Originally the mean height between the core and the IHX is $4.2 \mathrm{~m}$. For the analysis it has been modified in a range of $\pm 10 \%$ of the nominal.

This parameter affects directly the mass flow level in natural convection, in a $5 \%$ of the nominal, as the mean height of heat exchange is modified affecting to the $\Delta T$ between the two parts. Figure 17 shows the remaining mass flow level in three cases. 


\section{Conclusions}

This article has shown the PPs modelling process of a sodium fast reactor and its coupling in both onedimensional and three-dimensional models. After checking the operation of pumps in stationary regime it has been simulated a design basis accident consisting of a ULOF.

In the one-dimensional model it has been able to compare the response of the system with a reference model (RELAP code) based on the pump coast-down curve. The results show that during the course of the transient both systems evolve in parallel, seeing the influence of the, very similar but not identical, coolant's mass flow reduction. In both models, the sodium has reached the boiling point due to the increased on the temperature and the modelling of the Hot Fuel Assembly, after this moment the code is no longer capable to calculate.

Afterwards, it has been shown the results for the threedimensional model in which the system has evolved in a homologous way to the one-dimensional model. In Figures 10, 11, 13 and 15, some instabilities have appeared on reaching the new equilibrium state requiring a thorough study to find out its origin.

Another objective to be achieved by simulating the total coast-down of the pumps was to check the remaining flow due to natural convection. The reached level (Fig. 7) has been lower than expected (7\%). This discrepancy is mainly due to system losses, particularly from fluid friction. It has been identified the need for a code review focused on the calculation of the fluid's friction drops adapting them to work with liquid metals.

Finally, there has been a sensitivity study focused on the moment of inertia of the pumps and the average difference existing between the intermediate zone of the core and the IHX. In the first one, the influence of this parameter appears during the reduction of the mass flow modifying the coast-down curve of the pump. Modifications of $\pm 10 \%$ produce variations of nearly $6 \%$ from the nominal. In the second study, the difference is most noticeable on reaching the stationary, in which variations of $\pm 10 \%$ produce differences in the flow rate in natural convection of nearly $5 \%$.

The realistic modelling of the pumps has upgraded a model that works closer to real conditions. Without pumps the system evolved subject to the imposition of a theoretical flow limiting partially the system response. Therefore, it has been obtained an evolution of the reactor before an accident in a more naturally way increasing the reliability and definition of the simulation.

\section{Nomenclature}

$\begin{array}{lll}\text { ESFR } & \text { European Sodium Fast Reactor } & \\ \text { CP-ESFR } & \begin{array}{l}\text { Collaborative Project European Sodium Fast } \\ \text { Reactor }\end{array} & \\ \text { IHX } & \text { intermediate heat exchanger } & \\ H & \text { pump height }\left(\mathrm{m}^{2} / \mathrm{s}^{2}, \mathrm{~N} \mathrm{~m} / \mathrm{kg}\right) & \\ Q & \text { pump mass flow }\left(\mathrm{m}^{3} / \mathrm{s}, \mathrm{kg} / \mathrm{s}\right) \\ \Omega & \text { pump speed }(\mathrm{rad} / \mathrm{s}, \mathrm{rpm}) \\ N & \text { nominal value } \\ \text { BOL } & \text { Beginning Of Life } \\ \text { DHR } & \text { decay heat removal } \\ \text { SG } & \text { steam generators } \\ \text { ULOF } & \text { Unprotected Loss Of Flow }\end{array}$

\section{References}

1. A. Vasile, G. Fiorini, European Commission - 7th Framework Programme, The Collaborative Project on European European Sodium Fast Reactor (CP-ESFR), Nucl. Eng. Des. 241, 3461 (2011)

2. A. Lázaro et al., Code assessment and modelling for Design Basis Accident Analysis of the European Sodium Fast Reactor design. Part I: System description, modelling and benchmarking, Nucl. Eng. Des. 266, 1 (2014)

3. A. Lázaro et al., Code assessment and modelling for Design Basis Accident analysis of the European Sodium Fast Reactor design. Part II: Optimised core and representative transients analysis, Nucl. Eng. Des. 277, 265 (2014)

4. D. Blanchet, L. Buiron, ESFR Working horse description, European Sodium Fast Reactor Consortium? Deliverable SP2.1.2.D1, 2009

5. K. Mikityuk, Heat transfer to liquid metal: review of data and correlations for tube bundles, Nucl. Eng. Des. 239, 680 (2009)

6. NRC, in Trace v5.0 Theory manual, Field Equations, Solution Methods, and Physical Models (Office for Nuclear Regulatory Research, Washington, 2012), Chap. 10 